ORIGINAL ARTICLE

\title{
FIRST MOLECULAR DETECTION AND VP7 (G) GENOTYPING OF GROUP A ROTAVIRUS BY SEMI-NESTED RT-PCR FROM SEWAGE IN NIGERIA
}

Babatunde Olanrewaju MOTAYO(1), Adekunle Johnson ADENIJI(1,2) \& Adedayo Omotayo FANEYE(1)

\begin{abstract}
SUMMARY
Rotavirus is the leading cause of viral gastroenteritis worldwide, and sewage is a major source of the virus dissemination in the environment. Our aim was to detect and genotype rotaviruses from sewages in Nigeria. One hundred and ninety sewage samples were collected between June 2014 and January 2015. The two phase concentration method using PEG 6000 and dextran was used to concentrate sewage samples following WHO protocols. Molecular detection was performed by RT-PCR, and VP7 genotyping by semi-nested multiplex PCR. A total of $14.2 \%(\mathrm{n}=27)$ samples tested positive. Monthly distribution showed that June to September had a lower rate (3.7\% to $7.4 \%$ ), while October to January recorded $11 \%$ to $26 \%$. Genotype G1 predominated followed by G8, G9, G4 and lastly G2, 7.4\% ( $\mathrm{n}=2)$ of isolates were nontypeable. This is the first report of rotavirus detection in sewages from Nigeria. Genotype G1 remains the most prevalent genotype. This observation calls for an effort by the governmental authorities to implement a molecular surveillance, both clinical and environmental, in order to provide vital information for the control and the vaccine efficacy not only in Nigeria, but globally.
\end{abstract}

KEYWORDS: Rotavirus; Sewage; VP7 genotyping; Nigeria.

\section{INTRODUCTION}

Viral gastroenteritis resulting from exposure to contaminated drinking and recreational waters have been reported worldwide ${ }^{1,2}$. Many workers have indicated the presence of enteric viruses such as rotavirus and noroviruses in urban human sewages ${ }^{3,4}$. Contamination of surface water with these viruses leading to public health consequences has also been previously reported ${ }^{5}$. Some studies such as the one from Kargar et $\mathrm{al}^{4}{ }^{4}$ have also shown the presence of rotavirus in treated sewage effluents. Globally, rotavirus is the leading cause of acute gastroenteritis in children of less than five years, and over half a million deaths annually ${ }^{6}$. Rotavirus is a non-enveloped RNA virus belonging to the Reoviridae family, the genome consists of 11 double-stranded segments, with six structural proteins forming three concentric layers ${ }^{1,7}$. The outer capsid consists of two neutralizing antigens, the G type (VP7) and a protease-sensitive P type (VP4). Rotaviruses strains have been classified using the molecular and antigenic properties of these two proteins ${ }^{1,8}$.

In Nigeria, it has been estimated that over 160,000 deaths are associated with diarrhea in children of less than five years of age 9 Presently, there are two licensed rotavirus vaccines, the Rotateq, which confers protection against [P5]G1-4 and [P8]G6 strains, and Rotarix, that is protective against [P8]G $1^{10,11}$. In Nigeria, Rotarix vaccine is available but still not included in the National Expanded Immunization Program. Molecular epidemiology has shown the presence of genotypes G1[P8], G3[P8] amongst others in Nigeria ${ }^{12-15}$. Rotaviruses have been shown to persist and survive different physicochemical treatment processes during sewage treatment ${ }^{16,17}$. It is therefore essential to study the role of sewage contamination with rotaviruses, and their possible link to human outbreaks through environmental contamination of rivers, dams and irrigation channels. The aim of this study was to detect the presence of group A rotaviruses in sewage and determine the circulating $\mathrm{G}$ genotypes recovered from sewages in Nigeria.

\section{MATERIALS AND METHODS}

\section{Study Design}

The current study is a prospective analysis of sewage from five states in Nigeria namely, Sokoto, Kano, Brono, Abuja and Lagos.

Sewage samples were collected by the grab method in a white one liter keg and transported to the Laboratory under reverse cold chain conditions 
Motayo BO, Adeniji AJ, Faneye AO. First molecular detection and VP7 (G) genotyping of group A rotavirus by semi-nested RT-PCR from sewage in Nigeria. Rev Inst Med Trop Sao Paulo. 2016;58:74.

for processing. The cluster sampling technique was adopted following the protocol of the Polio Environmental Surveillance Program ${ }^{18}$.

\section{Sewage concentration}

Sewage samples were concentrated by using polyethylene glycol 6000, dextran, NaCL using a two-phase concentration method described by the guidelines for environmental surveillance for Poliovirus circulation ${ }^{18}$. Briefly each sewage sample was centrifuged at $1,500 \mathrm{~g}$ for $10 \mathrm{~min}$, then $400 \mathrm{~mL}$ of the upper supernatant was concentrated with a mixture of polyethylene glycol 6000, dextran $20 \%$ and NaCL 5M. Overnight incubation at $4{ }^{\circ} \mathrm{C}$ was carried out in a separation funnel, and a standard volume of $4 \mathrm{~mL}$ was harvested combining the bottom and the hazy interphase ${ }^{18}$.

\section{RNA extraction and cDNA synthesis}

Viral RNA was extracted beginning with PEG 6000 and dextranconcentrated sewage samples using a kit based on silica gel spin columns, Total RNA purification Kit by Jena Bioscience ${ }^{\circledR}$ GmbH, Frankfurt, Germany. Extracted RNA was transcribed into cDNA using Red Load Taq Master/high yeild by Jena Bioscience ${ }^{\circledR}$ GmbH, Frankfurt, Germany, according to manufacturer's instructions. Briefly $5 \mu \mathrm{L}$ of template RNA was added to $8 \mu \mathrm{L}$ of the cDNA synthesis mixture containing $4 \mu \mathrm{L}$ of RT buffer, $1 \mu \mathrm{L}$ of each dNTPs, DTT, RNase inhibitor, $0.5 \mu \mathrm{L}$ each of random hexamers and the RT enzyme (200 units). To this, $7 \mu \mathrm{L}$ of nuclease-free $\mathrm{H} 2 \mathrm{O}$ was added to a final volume of $20 \mu \mathrm{L}$. The reaction mixture was incubated at $42{ }^{\circ} \mathrm{C}$ for $10 \mathrm{~min}$ then, at $50{ }^{\circ} \mathrm{C}$ for $60 \mathrm{~min}$.

\section{Rotavirus detection and VP7 genotyping by semi-nested multiplex PCR}

Rotavirus detection was performed using the primers VP7f and $\mathrm{VP} 7 \mathrm{r}^{19}$. Genotyping was performed according to the protocol described by Rodriguez-Daiz et al. ${ }^{19}$. For the PCR detection, $4 \mu \mathrm{L}$ of cDNA was added to a reaction mixture of $21 \mu \mathrm{L}$ consisting of $5 \mu \mathrm{L}$ of the Red load
Taq Master/high yeild mix from Jena Bioscience ${ }^{\circledR} \mathrm{GmbH}$, Frankfurt, Germany, $0.2 \mu \mathrm{M}$ of each of the first-round primers (Table 1) and $14 \mu \mathrm{L}$ of nuclease-free $\mathrm{H}_{2} 0$. The second round of amplification consisted of the same volume of the red load PCR mix and $1 \mu \mathrm{L}$ of each of the genotypespecific primers, and the reverse primer of the first-round reaction. Primer positions and sequences are shown in Table 1. Cycling conditions were performed according to the protocol of Rodriguez-Diaz et al. ${ }^{19}$. All the samples were tested in duplicate before genotypes were assigned.

\section{Amplicon purification and sequencing}

Representative samples of the amplification products corresponding to each of the identified rotavirus genotypes were purified using PCR Purification Kit by Jena Bioscience $\AA$ GmbH, Frankfurt, Germany amplicon purification Kit, following the manufacturer's instructions. Purified amplicons were shipped to Inqaba Bioscience Inc, Pretoria, South Africa, for DNA sequencing performed using the second-round PCR primers.

\section{Sequence assembly and Phylogenetic analysis}

Sequences were verified using the Chromas Lite software, version 2 (www.techelysium.com.au), and assembled into contigs using the Bioedit software (www.mbio.ncsu.edu/bioedit/). Strains were determined by BLAST (Basic Local Alignment Search Tool) http://blast.ncbi.nlm.nih. gov/Blast.cgi from the National Center for Biotechnology Information (NCBI) and genotyped using the Rota $\mathrm{C}$ software, version 2.0 (www. rotac.regatools.be). Sequences were aligned along with other reference rotaviruses sequences retrieved from GenBank, using the CLUSTAL W program of the MEGA 5 software (www.megasofware.net). A neighbor joining tree was constructed with 1,000 bootstrap replicates using the Mega 5 software (www.megasoftware.com).

\section{Nucleotide sequence accession numbers}

Sequenced amplification products generated from this study have

Table 1

Molecular weight of amplification products and primer sequences for rotaviruses VP7 (G) genotyping by semi-nested RT-PCR according to Rodriguez-Diaz et al. ${ }^{19}$, in sewage samples from Nigeria

\begin{tabular}{|c|c|c|c|c|}
\hline Genotype & Primer name & Primer sequence 5'-3' & Nucleotide position & Molecular weight (bp) \\
\hline VP7 (G) $1^{\text {st }}$ rnd & VP7 F & ATGTAGGTATTGAATATACCAC & $49-71$ & \\
\hline VP7 (G) $1^{\text {st }}$ rnd & VP7 R & AACTTGCCACCATTTTTTCC & 914-933 & 884 \\
\hline $\mathrm{VP7}(\mathrm{G})$ & VP7 R & AACTTGCCACCATTTTTTCC & 914-933 & \\
\hline G1 & aBT1 & CAAGTACTCAATGAATGATGG & $314-335$ & 619 \\
\hline $\mathrm{G} 2$ & ACT2 & CAATGATATTAACACATTTTCTGTG & 411-435 & 522 \\
\hline G3 & G3 & ACGAACTCAACACGAGAGG & $250-269$ & 683 \\
\hline G4 & aDT4 & CGTTTCTGGTGAGGAGTTG & $480-499$ & 453 \\
\hline G8 & aAT8 & GTCACACCATTTGTAAATTGC & $178-198$ & 755 \\
\hline G9 & aFT9 & CTAGATGTAACTACAACTAC & $757-776$ & 176 \\
\hline G10 & G10 & ATGTCAGACTACARATACTGG & $666-687$ & 267 \\
\hline
\end{tabular}

Rnd - round; bp - base pairs 

2016;58:74.

been deposited in GenBank with the accession numbers KU 88451 and KU 88454.

\section{Statistical analysis}

Data were analyzed and tested for significance using the Chi-square test. The statistical software SPSS version 18.0 (IBM, New York, USA) was used for all the analysis and a $p$ value of $p<0.05$ was considered significant.

\section{RESULTS}

\section{Detection and seasonal distribution}

A total of 190 sewage samples were processed and tested. Rotavirus was detected in $14.2 \%(n=27)$ of the samples by RT-PCR. Monthly distribution of rotavirus showed a significant difference between the rainy months from June October, and the early dry months from November to January $(p<0.05)$ (Fig. 1). The months of June and July recorded a $3.7 \%$ isolation rate, August and September $7.4 \%$, and there was a sharp rise in the detection rate in November (18.5\%), December $(22.2 \%)$ and January $(26 \%)$. The regional distribution of rotaviruses is shown in Figure 2, with the northern region, comprising Kano and Borno States recording the highest rates $(16.2 \% ; \mathrm{n}=17)$, followed by southern region, composed of Lagos State $(13.6 \%$; $\mathrm{n}=6)$, and lastly Central Nigeria Abuja $(12.2 \% ; \mathrm{n}=4)$.

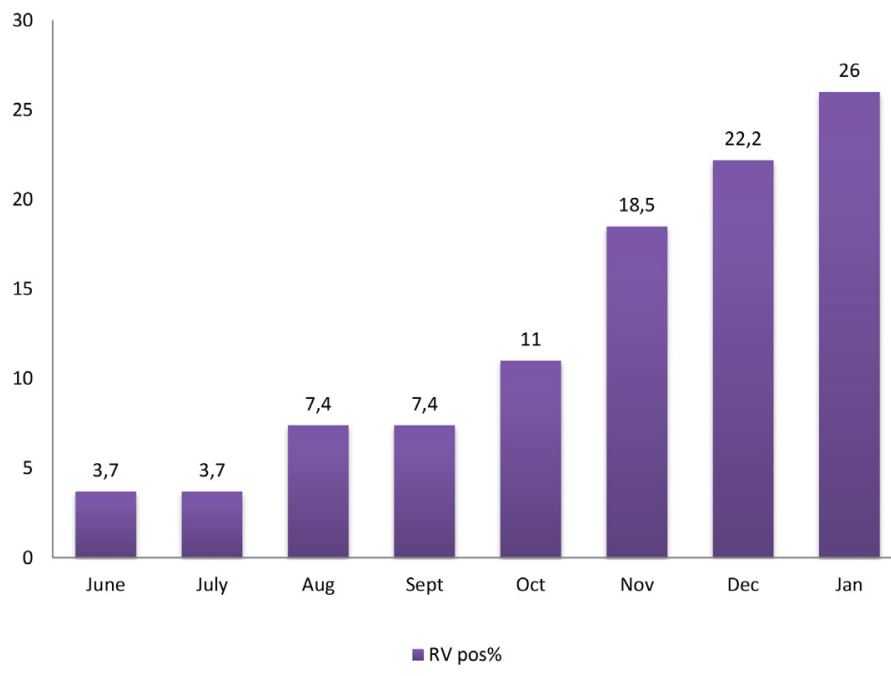

Fig. 1 - Rotavirus distribution from sewage in Nigeria June 2014 to January 2015.

\section{Genotype distribution}

The genotype distribution of rotaviruses strains showed isolates with single genotype specificity that were responsible for $70.4 \%(\mathrm{n}=$ 19), isolates with mixed genotype specificity accounting for $22.2 \%$ (n $=6)$, while $7.6 \%(n=2)$ were nontypeable isolates as shown in Table 2 .

Genotype G1 was the overall most predominant isolate accounting for $40.7 \%(n=11)$ of the total, when both mono and mixed isolates were considered (Table 2), followed by G8 $(26 \%$; $n=7)$, G9 and G3 $(14.8 \% ; n=4), \mathrm{G} 4(11 \% ; \mathrm{n}=3)$ and lastly G2 $(7.4 \% ; \mathrm{n}=2)$, (Table 3$)$.

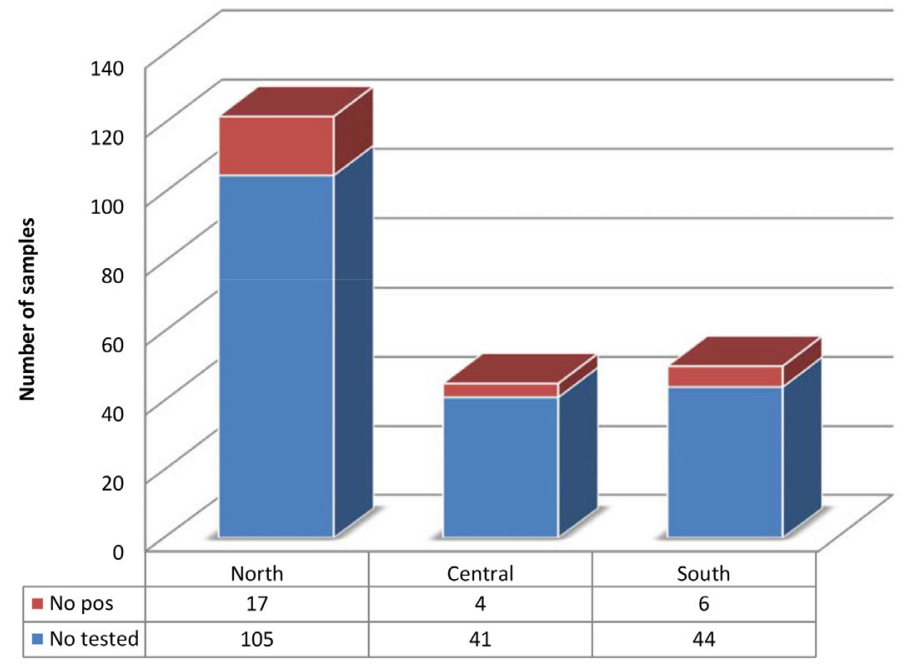

Fig. 2 - Stacked bar chart showing number of samples tested for rotavirus RNA versus number of rotavirus RNA positive samples according to geographical region. North represents Sokoto, Bornu and Kano States. Central represents Abuja, and south represents Lagos State.

Nontypeable strains corresponded to two out of the 27 (7.4\%) isolates (Table 3). The genotype distribution in relation to seasonality showed that all the genotypes except for genotype 4 and 3 displayed a higher level of circulation during the dry season than the rainy season (Fig. 3).

\section{Sequence and Phylogenetic analysis}

Samples representative of each genotype were sequenced, then submitted to sequence assembly and BLASTn search: two genotypes were distinctly identified, genotype G1, and genotype G3, samples representing genotypes $\mathrm{G} 9, \mathrm{G} 3$ and $\mathrm{G} 4$ were not readable due to a low yield of amplified DNA. Phylogenetic analysis shown in Figure 4 revealed that G1 isolates have clustered with a recently identified Nigeria isolate, as well with a Chinese isolate. It has also been shown that the G3 isolate clustered closely with G3 isolates from Ghana.

\section{DISCUSSION}

The current study detected the presence of rotaviruses in sewage from Nigeria for the first time. A total of $14.2 \%$ of the sewage samples collected during the study period tested positive, this result is similar to that of a recent study from Shiraz, conducted in Iran, in which 25\% (n $=15$ ) of urban and hospital sewage samples tested positive for group A rotaviruses ${ }^{4}$. Other studies have reported detection rates from $11 \%$ to $42 \%{ }^{20,21}$. In our study we used molecular methods rather than Enzyme Immunoassays (EIA) because of the higher sensitivity and specificity of PCR to detect fewer copies of enteric viruses such as rotaviruses from environmental sources ${ }^{2,17}$.

In a study from Argentina, a very high detection rate was reported using qPCR technique, with 32 out of 35 samples (91.4\%) testing positive $^{2}$. This is one example of the high level of efficiency of molecular methods to detect enteric viruses from environmental sources.

The virus concentration method used in this study, the two-phase concentration method using PEG 6000 and dextran as resins with NaCL is 
Motayo BO, Adeniji AJ, Faneye AO. First molecular detection and VP7 (G) genotyping of group A rotavirus by semi-nested RT-PCR from sewage in Nigeria. Rev Inst Med Trop Sao Paulo. 2016;58:74.

Table 2

Monthly isolation rate and genotype distribution of group A rotaviruses detected in sewage from Nigeria

\begin{tabular}{|c|c|c|c|c|c|c|c|c|c|}
\hline \multirow{2}{*}{ Month } & \multirow{2}{*}{$\begin{array}{c}\text { Positive/ } \\
\text { total number }\end{array}$} & \multicolumn{8}{|c|}{ G genotype } \\
\hline & & G1 & $\mathrm{G} 2$ & G3 & G4 & G8 & G9 & $\mathrm{Nt}$ & Mixed G \\
\hline June & $1 / 21$ & + & - & - & - & - & - & - & - \\
\hline July & $1 / 18$ & - & + & - & - & - & - & - & - \\
\hline Aug. & $2 / 23$ & + & + & - & - & - & - & - & - \\
\hline Sept. & $2 / 25$ & - & - & + & - & - & + & - & - \\
\hline Oct. & $3 / 24$ & - & - & - & - & + & - & + & + \\
\hline Nov. & $5 / 28$ & + & - & + & + & - & + & - & + \\
\hline Dec. & $6 / 26$ & + & - & + & - & - & + & + & + \\
\hline Jan. & $7 / 25$ & + & - & + & + & - & - & - & + \\
\hline
\end{tabular}

represents rotaviruses positive samples; $[+]$ represents positive results; $[-]$ represents negative results; $(\mathrm{N})$ represents the number of samples tested per month. $[\mathrm{Nt}]=$ nontypeable strain; [Mixed G] represents mixed genotypes.

Table 3

Distribution of rotaviruses $\mathrm{G}$ genotype specificities in sewage samples from Nigeria

\begin{tabular}{lcccccccc}
\hline \multicolumn{7}{c}{ Single genotype distribution } \\
\hline G-type & $\mathrm{G} 1$ & $\mathrm{G} 2$ & $\mathrm{G} 3$ & $\mathrm{G} 4$ & $\mathrm{G} 8$ & $\mathrm{G} 9$ & $\mathrm{G} 10$ \\
\hline $\mathrm{N}(\%)$ & $7(26)$ & $2(7.4)$ & $2(7.4)$ & $1(3.7)$ & $3(11)$ & $4(14.8)$ & $0(0)$ \\
\hline \multicolumn{7}{c}{ Mixed genotype distribution } \\
\hline G-type & $\mathrm{G} 1 ; \mathrm{G} 3$ & $\mathrm{G} 1 ; \mathrm{G} 8$ & $\mathrm{G} 4 ; \mathrm{G} 8$ & $\mathrm{G} 1 ; \mathrm{G} 3$ & $\mathrm{G} 8 ; \mathrm{G} 1$ & $\mathrm{G} 9 ; \mathrm{G} 1$ & $\mathrm{Nt}$ \\
\hline $\mathrm{N}(\%)$ & $2(7.4)$ & $2(7.4)$ & $2(7.4)$ & $0(0)$ & $0(0)$ & $0(0)$ & $2(7.4)$ \\
\hline
\end{tabular}

$\mathrm{Nt}=$ nontypeable isolates

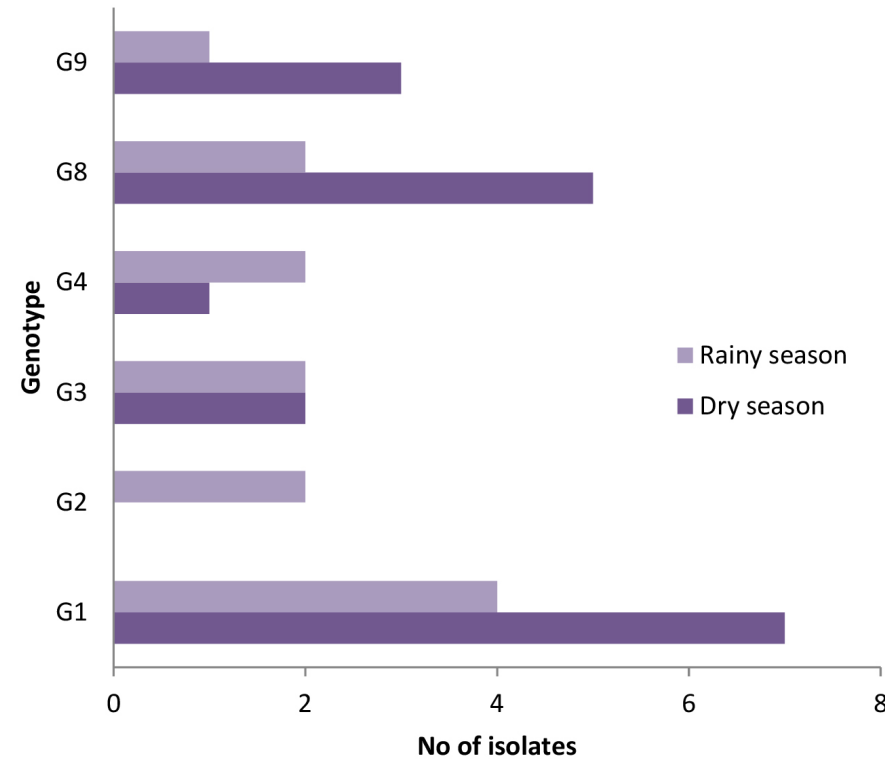

Fig. 3 - Seasonal distribution of rotavirus genotypes isolated from sewage from in Nigeria

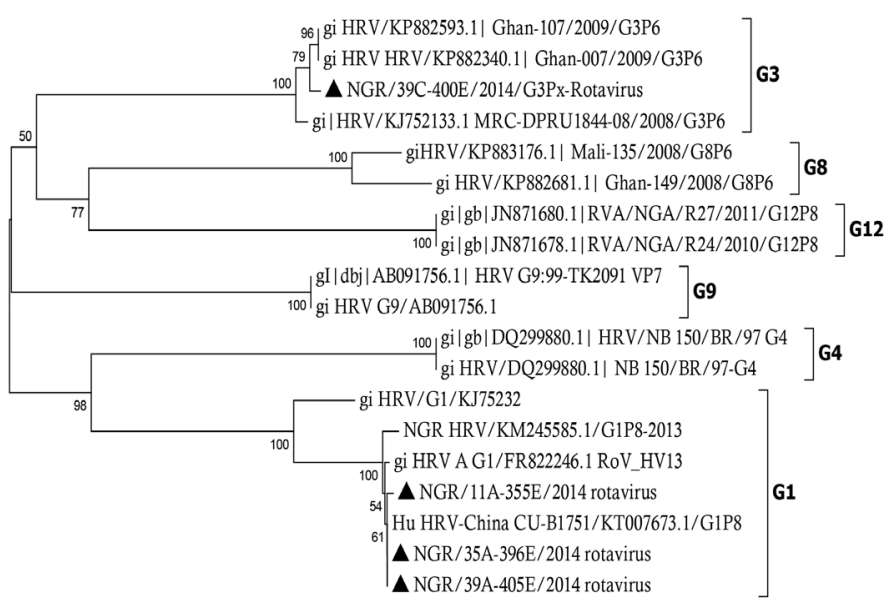

$\longmapsto 0.02$

Fig. 4 - Phylogenetic relationship of partial VP7 gene sequences of rotaviruses. The newly sequenced strains from this study are indicated in black triangles, genotype assignments are indicated in bold letters by the right. GenBank accession numbers of the reference rotavirus sequences are indicated in the tree. 


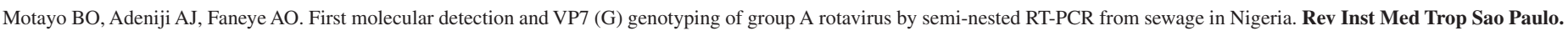
2016;58:74.

a very efficient recovery method to be applied to viruses from water and environmental sources such as sewage ${ }^{22}$. This method has been reported to enhance the yield of intact virions ${ }^{4}$. Hovi et al. ${ }^{23}$ have demonstrated that the virus concentration from water samples can be increased by up to 100 fold using the two-phase method. The monthly distribution of rotaviruses in sewage from Nigeria revealed a low detection rate in the months of June to September (Fig. 1), with June and July having the lowest rates of all $(3.7 \%)$. These months coincides with the peak of the rainy season in Nigeria when humidity and precipitations are very high. There are also heavy rainfalls during these months. However detection has increased steadily from September to January of the next year, coinciding with the beginning of the dry season otherwise known as harmattan in Nigeria. This observation shows that rotaviruses transmission can occur in both the rainy season and the dry season in Nigeria. This seasonality in rotaviruses detection has also been reported in the context of other viruses, particularly measles and influenza ${ }^{24,25}$, however detection rates more than doubled during the dry months. This finding is an indicator of a higher risk of transmission during the dry season. Since rotaviruses can be shed by both symptomatic and asymptomatic people ${ }^{1}$, this observed pattern does not necessarily suggest a higher level of rotaviruses outbreaks during the dry months. Some other factors such as general hygiene, nutrition and heard immunity also play a role before disease manifestation occurs. Previous studies in other parts of the world such as the study carried out in Argentina showed a similar seasonal pattern of rotavirus detection in sewage, although there was no statistically significant association ${ }^{2}$. This observed trend in seasonality has been proposed by Bishop ${ }^{26}$, so that the virus might be spread by ingested aerosolized particles. The consequence of the currently observed trend in rotaviruses seasonal detection is that the disease transmission is most likely to increase during the dry season because of the poor sanitary conditions resulting in scarcity of water particularly in rural areas. The geographical distribution results have found a higher detection rate in the northern states compared with the central and southwestern state of Lagos (Fig. 2). This finding does not necessarily mean that Rotavirus burden is higher in Northern Nigeria, because a nationwide survey has never been carried out and cases of rotaviruses leading to diarrhea continue to be reported across the country. However, our results have shown that rotavirus transmission occurs across the country.

The genotype distribution revealed that genotype G1 was the predominant circulating genotype. This is in line with previous reports from Nigeria which have shown G1 to be the main circulating strain among diarrheic children from different parts of Nigeria ${ }^{12,14,15,27,28}$. The global genotype distribution has also identified G1[P8] to be the predominant circulating strain ${ }^{7}$. Genotypes G2, G3, G4, and G8 that have been previously reported, have also been identified among the typed strains $^{9,12,14,27}$. A significant number of mixed genotypes $(22.2 \% ; n=6)$ were identified in the present study, this is in line with other studies on clinical samples from Nigeria ${ }^{15,30}$. In addition, genotype G9 isolates, that have already been reported, were also identified in this study ${ }^{13,15,28}$. Apart from the few episodes in which G9 has been retrieved, G9 rotaviruses have been rarely identified in Nigeria, despite their clinical and epidemiologic global importance. The number of nontypeable strains recorded was $7.4 \%$ $(\mathrm{n}=2)$ and this can be attributed to a high level of rotaviruses diversity in Nigeria, as previously reported ${ }^{13,15}$. This finding has also been associated with an immune evasion pressure in countries where rotavirus vaccination has been included in the expanded program for immunization (EPI) ${ }^{29}$. This is however not the case in Nigeria, as rotavirus vaccines have not yet been included in the EPI program, and are available only to those who can afford the vaccination. The seasonal distribution of $\mathrm{G}$ genotypes showed a higher number of G1, G8 and G9 genotypes identified during the dry season than during the rainy season (Fig. 3). Genotype G4 and $\mathrm{G} 2$, however, displayed a different pattern with the rainy season having a higher distribution. Analysis of representative rotaviruses sequences has correctly identified two genotypes, G1 and G3. Blast search results for the sequences presenting high bootstrap similarity values to Asian G1 rotaviruses isolates, showed that our G3 isolate had a high similarity bootstrap value in comparison with other G3 strains from Asia. The phylogenetic analysis showed a distinct clustering of our G1 isolates with other representative G1 isolates from China and Nigeria (Fig. 4). Our G3 isolate, however, has clustered with other G3 isolates from Ghana, West Africa, with a high (79\%) bootstrap value (Fig. 4). One limitation of this study was our inability to analyze sequences of other representative rotaviruses genotypes, due to unreadable sequences resulting from a low yield of the amplification products after purification, however, all the samples had been retested twice before genotypes were assigned.

The results from our study demonstrated, for the first time, the diversity of rotaviruses genotypes in sewage from Nigeria. Rotavirus G1 remains the predominant genotype circulating in Nigeria, genotype G9 was also detected. There were also a number of nontypeable rotaviruses strains, which may correspond to highly divergent genotypes. This observation calls for an effort by the governmental authorities to implement a molecular surveillance, both clinical and environmental, in order to provide vital information for the control and the vaccine efficacy not only in Nigeria, but globally.

\section{ACKNOWLEDGEMENTS}

We thank Professor David O. Olaleye for his assistance with the molecular analysis. We also thank the entire staff of the WHO poliovirus laboratory of Ibadan, Nigeria, for their valuable technical assistance. B. O. M. is a $\mathrm{PhD}$ student studying the molecular epidemiology and evolution of rotaviruses from environmental sources. This study is part of his $\mathrm{PhD}$ thesis.

\section{CONFLICT OF INTEREST}

The authors declare that there are no conflicts of interest regarding this research.

\section{REFERENCES}

1. Estes MK, Greenberg HB. Astroviridea. In: Knipe DM, Howley PM, editors. Fields' virology. $6^{\text {th }}$ ed. Philadelphia: Lippincot Williams \& Wilkins; 2013. p.1347-86.

2. Barril PA, Fumian TM, Prez VE, Gil PI, Martinez LC, Giordano MO, et al. Rotavirus seasonality in urban sewage from Argentina: effect of metrological variables on the viral load and the genetic diversity. Environ Res. 2015;138:409-15.

3. Villena C, El-Senousy WM, Abad FX, Pinto RM, Bosch A. Group A rotavirus in sewage samples from Barcelona and Cairo: emergence of unusual genotypes. Appl Environ Microbiol. 2003;69:3919-23.

4. Kargar M, Javdani N, Najafi A, Tahamtan Y. First molecular detection of group A rotavirus in urban and hospital sewage systems by nested RT-PCR in Shiraz, Iran. J Environ Health Sci Eng. 2013;11:4. 

2016;58:74.

5. Lodder WJ, de Roda Husman AM. Presence of noroviruses and other enteric viruses in sewage and surface waters in the Netherlands. Appl Environ Microbiol. 2005;71:145361.

6. Parasha UD, Burton A, Lanata C, Boschi-Pinto C, Shibuya K, Steele D, et al. Global mortality associated with rotavirus disease among children in 2004. J Infect Dis. 2009;200 Suppl 1:S9-S15.

7. Angel J, Franco MA, Greenberg HB. Rotavirus vaccines: recent developments and future considerations. Nat Rev Microbiol. 2007;5:529-39.

8. Rahman M, Matthihesses J, Nahar S, Podder G, Sack DA, Azim T, et al. Characterization of a novel P[25],G11, human group a rotavirus. J Clin Microbiol. 2005;43:3208-12

9. Aminu M, Esona MD, Gayer A, Steele AD. Epidemiology of rotavirus and astrovirus infection in children in northwestern, Nigeria. Ann Afr Med. 2008;7:168-74.

10. Vesikari T, Matson DO, Dennehy P, Van Danme P, Santosham M, Rodriguez Z, et al. Safety and efficacy of a pentavalent human-bovine (WC3) reassortment rotavirus vaccine. N Eng J Med. 2006;354;23-33.

11. Ruiz-Palacios GM, Pérez-Schael I, Velázquez FR, Abate H, Breuer T, Clemens SC, et al. Safety and efficacy of an attenuated vaccine against severe rotavirus gastroenteritis. N Eng J Med. 2006;354:11-22.

12. Adah MI, Olaleye OD. Distribution of serotypes and genotypes of rotavirus in Nigerian children. Niger J Pediatr. 1998;25:20-4.

13. Adah MI, Wade A, Taniguchi K. Molecular epidemiology of rotaviruses in Nigeria: detection of unusual strains with G2P[6] and G8P[1] specificities. J Clin Microbiol. 2001;39:3969-75.

14. Audu R, Omilabu SA, Peenze I, Steele D. Viral diarrhoea in children in two districts in Nigeria. Cent Afr J Med. 2002;48:59-63.

15. Aminu M, Page NA, Ahmad AA, Umoh JU, Dewar J, Steele AD. Diversity of Rotavirus VP7 and VP4 genotypes in Northwestern Nigeria. J Infect Dis. 2010;202 Suppl 1:S198-S204.

16. Dubois E, Le Guyader F, Haugarreau L, Kopecka H, Cormier M, Pommepuy M. Molecular epidemiological survey of rotaviruses in sewage by reverse transcriptase semi-nested PCR and restriction fragment length polymorphism assay. Appl Environ Microbiol. 1997;63:1794-800

17. Prado T, Silva DM, Guilayn WC, Rose TL, Gaspar AM, Miagostovich MP. Quantification and molecular characterization of enteric viruses detected in effluents from two hospitals wastewater treatment plants. Water Res. 2011;45:1287-97.
18. World Health Organization. Guidelines for environmental surveillance of poliovirus circulation. Geneva; WHO; 2003.

19. Rodriguez-Diaz J, Querales L, Caraballo L, Vizzi E, Liprandi F, Takiff H, Betancourt WQ. Detection and characterization of water borne gastroenteritis viruses in sewage and sewage polluted waters in Caracas, Venezuela. Appl Env Microbiol. 2009;75:38794.

20. He XQ, Cheng L, Zang DY, Li W, Xie XM, Ma M, et al. First detection of group A rotaviruses in drinking water sources in Beijing, China. Bull Environ Contam Toxicol. 2009;83:120-4.

21. Grassi T, Bagordo F, Idolo A, Lugoli F, Gabutti G, De Donno A. Rotavirus detection in environmental water samples by tangential flow ultrafiltration and RT nested-PCR. Environ Monit Assess. 2010;164:199-205.

22. Adeniji JA, Faleye TO. Isolation and identification of enteroviruses from sewage and sewage-contaminated waters in Lagos, Nigeria. Food Environ Virol. 2014;6:75-86.

23. Hovi T, Stenvik M, Partanen H, Kangas A. Poliovirus surveillance by examining sewage specimens. Quantitative recovery of the virus after introduction into sewerage at remote upstream location. Epidemiol Infect. 2001;127:101-6.

24. Haffejee IE. The epidemiology of rotavirus infections: a global perspective. J Pediat Gastroentrol Nutr. 1995;20:275-86.

25. Faneye AO, Adeniji JA, Olusola BA, Motayo BO, Akintunde GB. Measles virus infection among vaccinated and unvaccinated children in Nigeria. Viral Immunol. 2015;28:304-8.

26. Bishop RF. Natural history of human rotavirus infection. Arch Virol Suppl 1996;12:119-28

27. Adah MI, Rohwedde A, Olaleye DO, Durojaiye OA, Werchau H. Serotype of Nigerian rotavirus strains. Trop Med Int Health. 1997;2:363-70.

28. Ayolabi CI, Ojo DA, Armah GE. Electropherotypes and G types of group A rotaviruses detected in children with diarrhea in Lagos, Nigeria. ISRN Virol. 2013;2013:179871.

29. Pietsch C, Schuster V, Liebert UG. A hospital based study on inter- and intragenotypic diversity of human rotavius A VP4 and VP7 gene segments, Germany. J Clin Virol. 2011;50:136-41.

Received: 28 September 2015

Accepted: 10 May 2016 